\title{
Diplomata Militaria Del Museo de Huelva
}

\author{
Julián GonZÁlez FernándeZ \\ Universidad de Sevilla \\ JaVier Bermejo MeléndeZ \\ Universidad de Huelva
}

Recibido: 29/01/2016

Revisado: 28/03/2016

Aceptado: 28/03/2016

Publicado: 30/06/2016

\section{RESUMEN}

Se presenta en esta aportación una pequeña colección epigráfica correspondiente a diplomas militares depositada actualmente en el Museo de Huelva y cuya procedencia se desconoce con exactitud. Dicha colección está compuesta por diversas piezas con distinto grado de conservación y contenido, que permite ampliar la nómina de este tipo de documentos jurídicos en bronce para el caso de Hispania.

\section{ABSTRACT}

This contribution comes in a small epigraphic collection corresponding to military diplomas currently deposited in the Museum of Huelva. This collection consists of several pieces with different degrees of preservation and content, that extends the payroll of such legal documents in bronze for the case of Hispania.
Palabras Clave

diplomas; ejército; romanización; ciudadanía; epigrafía.

\section{KEYWORDS}

diploma; army; romanization; citizenship; epigraphy.

julgonzalez@us.es

javier.bermejo@dhis1.uhu.es 
Entre las piezas que constituyen la rica colección del Museo de Huelva hay que destacar la existencia de nueve diplomas militares en un estado muy fragmentado, de cuyo lugar de procedencia y circunstancias de su hallazgo carecemos de datos precisos, pues no existe referencia alguna en el libro de registro del Museo. Una de ellas, perteneciente a una anónima unidad militar destacada en la provincia de Mauritania Tingitana y fechable probablemente entre los años 157/159 en el reinado de Antonino Pío, será publicada próximamente en la revista Epigraphica (González y Bermejo, ep). De los ocho restantes, dos son copias de constitutiones de Trajano, uno de Adriano, tres de Antonino Pío y los dos últimos de emperadores desconocidos.

1. Diploma de una constitutio de Trajano PROMULGADA EN 116/117 D.C.

Pequeño fragmento de bronce de la tabella I de un diploma militar, de forma casi cuadrada, que ha conservado uno de sus ángulos y mide $\mathbf{0 , 6} \mathrm{cm}$ de altura, $\mathbf{0 , 5} \mathrm{cm}$ de anchura y $0,1 \mathrm{~cm}$ de grosor. La altura de las letras oscila en $4,8-5 \mathrm{~mm}$ en su cara exterior y $4 \mathrm{~mm}$ en la interior; conserva tres líneas de texto en su cara exterior y dos en la interior. Se encuentra depositado en el Museo Provincial de Huelva, núm. de inventario 10.623 (Fig. 1).

Cara exterior: A pesar de la brevedad del texto conservado, el comienzo de las 11.2-3: IANV y $\mathrm{PON}$, nos permitirán concretar no sólo el nombre del emperador autor de la constitutio, sino incluso una fecha probable. En efecto, el comienzo IANV nos remite inmediatamente a TRA/IANVS, cognomen presente en la onomástica de Trajano y Adriano, pero la filiación del último: Imp Caesar divi Traiani Parthici f. divi Nervae nepos Trasobrepasa en mucho la probable longitud de la 1.1 Por otra parte, la determinación del pontificado al comienzo de la 1.3 revela que los títulos triunfales del emperador deben llegar hasta el final de esa línea, pero los habituales hasta el año 114, cuando el Senado concede a Trajano el título de Optimus princeps: Germ(anicus) Dacic(us) resultan demasiado cortos, por lo que sin duda hemos de incluir ese título en los honores del emperador. La inclusión de Optimus en la titulación imperial nos permitiría completar la línea de una manera coherente, con lo que tendríamos el año 114 d.C. como una fecha post quem para la datación del diploma. Pero incluso con esta adición, el texto nos parece demasiado reducido, sobre todo cuando las letras de la 1.2 son algo más pequeñas y separadas por un espacio menor, por lo que muy probablemente debería figurar también el título de Parthic(us), que el Senado el concedió el año 116 por sus triunfos en Oriente, con lo tendríamos la copia de una constitutio de Trajano promulgada el año 116 o 117.
Cara interior

$$
\begin{aligned}
& \operatorname{IMP}[---] \\
& \text { AVG[- - }]
\end{aligned}
$$

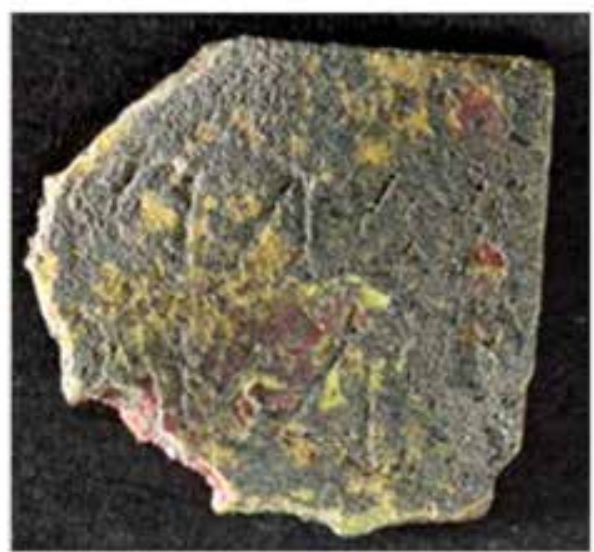

Cara exterior

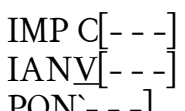

PON-- - ]

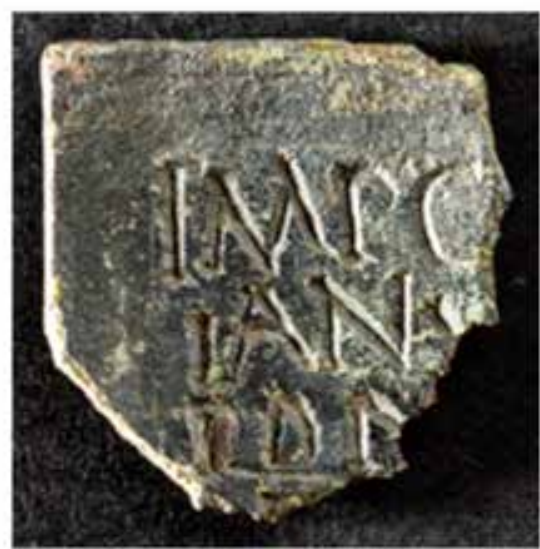

Fig. 1. Detalle del diploma de época de Trajano 
Por todo ello proponemos la siguiente restitución:

Imp. C[aesar, divi Nervae f., Nerva Tra-]

ianu[s, Optimus Aug. Germ(anicus) Dacic(us)

Parthic(us)]

ponItif. max. trib. pot. XX/XXI, imp. XI/XIII, cos

VI p.p]

.....

Cara interior: El comienzo AVG de la 1.2 señala con claridad que los diversos elementos de la filiación del emperador han sido abreviados.

$\mathrm{Si}$ se acepta la fecha del 116/117 propuesta por nosotros, éste diploma se añadiría a la reducida nómina de constitutiones de estos años. Concretamente del año 116 contamos con cuatro diplomas, dos de la Raetia, uno de 21 de Febrero/8 de septiembre (RMDIII 155) y otro del 16 de Agosto (RMD IV 229); uno de la Pannonia Superior, sin fecha de la constitutio de la que era copia (CIL XVI 64) y un último de la Moesia Inferior, igualmente sin una datación concreta (cfr. Eck-Pangerl, 2008: 525-530). Del año 117 tan sólo conocemos una constitutio del 8 de septiembre a la que pertenecen dos diplomas de la Germania Superior (cfr. CIL XVI 62-63; Roxan, RMD III, p. 237).

Cara interior

$$
[---] \text { LI F } P
$$$$
\text { - - . - - }
$$

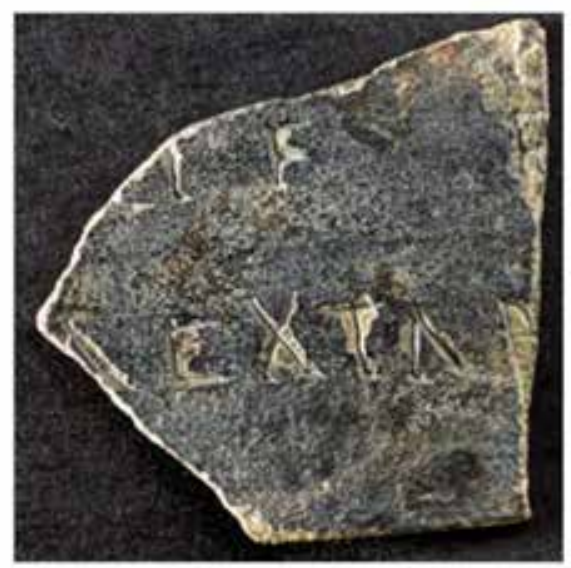

Fig. 2. Detalle del siguiente diploma trajaneo.
2. Diploma de una constitutio de Trajano PROMULGADA EN 105/107 D.C.

Pequeño fragmento de bronce que corresponde a la tabella II de un diploma militar, que ha conservado su margen superior, mide $2,1 \mathrm{~cm}$ de altura, $1,8 \mathrm{~cm}$ de anchura y $0,1 \mathrm{~cm}$ de grosor; la altura de las letras es de unos $5 \mathrm{~mm}$ Se trata de la tabella II de un diploma militar, que conserva dos líneas de texto en ambas caras. Se encuentra depositado en el MPH (Museo Provincial de Huelva), núm. de inv. 10.620 (Fig. 2).

Cara interior: A pesar de la ausencia de referencias al emperador que ha promulgado la constitutio, a la unidad en la que sirvió el veterano receptor del diploma o a la provincia en la que ésta había estado estacionada, sin embargo los datos aportados por nuestro diploma nos permiten, en nuestra opinión, aproximarnos a una datación bastante precisa del mismo. En efecto, la conservación del margen inferior de la parte interna de la tabella nos permite constatar que la línea conservada es la última del texto, y por lo tanto no hay espacio suficiente para completar la fórmula habitual: descriptum et recognitum ex tabula aenea quae fixa est Romae in muro post templum divi Aug(usti) ad Minervam. Esta apreciación se ve confirmada por el hecho de que la parte final de la fórmula que identificaba el lugar preciso en Roma donde se mostraba la constitutio (in muro post templum

Cara exterior

$$
\begin{aligned}
& {[---] \mathrm{VRBA}} \\
& {[---] \underline{\mathrm{ME}}}
\end{aligned}
$$

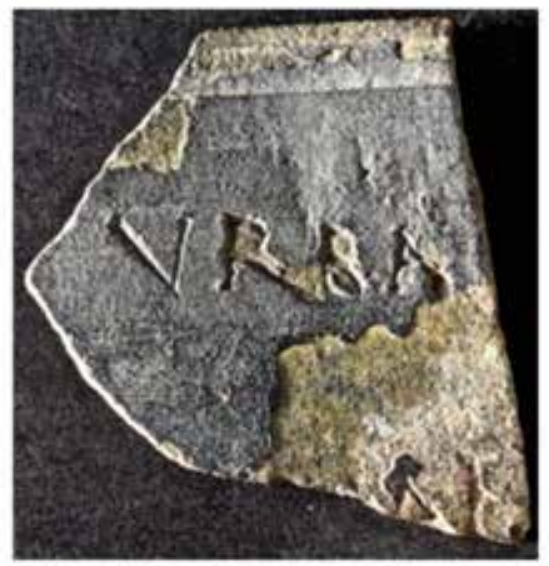


divi Aug(usti) ad Minervam) se omitió de las caras interiores de los diplomas conocidos entre los año 90 y 114 d.C. (CIL XVI 36, 61; RMD 86, 152).

\section{Cara exterior:}

Por otra parte, dentro del período anterior el cognomen Urbanus del primer testigo sólo está documentado en la filiación de Ti. Iulius Urbanus, atestiguado entre los años 105-129 (Cfr. Holder, $R M D \mathrm{~V}$, p. 941), lo que reduce notablemente la horquilla temporal anterior. La identificación del segundo testigo, de cuyo cognomen tan sólo se ha conservado la sílaba ME, nos ayudará como veremos a concretar aún más la fecha de nuestro diploma. En efecto, aunque hasta los años 134/138 los testigos no firman en un orden fijo (Morris y Roxan, 1977), existe una cierta tendencia a mantenerlos en un lugar estable durante algún tiempo. Así, por ejemplo, en todos los diplomas del año 105, de los que se ha conservado la tabella II, Iulius Urbanus aparece como primer testigo (CIL XVI, 49-50; RMD I, 8-9; RMD V, 339), en cambio, no ocurre lo mismo con el segundo testigo, que en los diplomas más antiguos, 12 de enero, es $P$. Caulius Gemellus (CIL XVI, 49; RMD V, 339) y en los tres restantes, de 13 de mayo, 1 de mayo/15 de julio y 24 de septiembre, respectivamente, éste ha sido sustituido por Q. Pompeius Homerus (CIL $\mathrm{XVI}, 50 ; R M D \mathrm{I} .8-9)$. Esta sustitución en principio no es determinante, pues ambos muestran en sus cognomina las sílaba ME. Posteriormente, en septiembre-diciembre del 107, la pareja Urbanus/ Homerus continúan ocupando los dos primeros lugares en sendos diplomas de la Moesia Inferior (RGZM 14 = Eck-Pangerl, 2008: 514-522).

Urbanus vuelve a estar documentado como primer testigo en los años 109, en un diploma de 14 de Octubre (RMD III, 148), 112, en otro de 29 de enero/29 de marzo $(R M D \mathrm{~V}, 344)$ y en el 113 , en uno de 16 de diciembre ( $R M D$ II, 86), pero en el primer testimonio el segundo testigo es $P$. Cornelius Alexander, y en los dos restantes $L$. Pullius Verecundus. Finalmente, del año 114 tenemos testimonios de dos constitutiones, una de 19 de julio, donde Urbanus vuelve al primer lugar, acompañado en el segundo por $P$. Caulius Vitalis (RMD I, 14; IV, 227) y una segunda de 1 de septiembre, donde ocupa el sexto lugar (CIL XVI, 61; RMD III, 152; V, 345-346).

Estos datos nos permiten considerar a nuestro diploma como copia de una constitutio de Trajano, cuya fecha muy probablemente oscile entre los años 105 y 107 , aunque tal vez haya que extender hasta el 108, ya que carecemos de datos concretos para los testigos de este año.

Las letras conservadas en la 1.1 de la cara interior corresponden, sin duda, a la filiación del veterano o de algún miembro de su familia.

Por ello, venimos a proponer la siguiente restitución:

Cara interior:

[Imp(erator) Caesar, divi Nervae f(ilius), Nerva Traianus Augustus Germ(anicus) Dacic(us), pont(ifex) max(imus), tribunic(ia) potest(ate) VIIII/ $X I$, imp(erator) IV/VI, co(n)s(ul) V, p(ater) p(atriae)

- - - -

[- - -]li f(ilius) P[- - ]

[Descriptum et recognitu]m ex tab[ula aenea] [quae fixa est Romae]

Cara exterior:

[Ti. Iulius] Urba[ni; [Q. Pompei Ho]me[ri]; [P. Cauli Restituti; P. Atini Amerimni; M. Iuli Clementis; Ti. Iuli Euphemi; P. Cauli Vitalis]. -.... .

3. Diploma de una constitutio de AdRiano para las tropas de Siria del 22 de marzo (MINUSCULA) 129 D.C.

Pequeño fragmento de bronce, que ha conservado uno de sus lados, en el que se aprecia unas hendiduras que funcionan a la manera de moldura. Mide $3,2 \mathrm{~cm}$ de altura, 2,6 cm de anchura y 0,7 cm de grosor; la altura de las letras es de unos $4 \mathrm{~mm}$. Se trata de la tabella II de un diploma militar, que contiene tres líneas de texto en su cara exterior y dos en la interior. Se encuentra depositado en el MPH, núm. Inv. 10.619 (Fig. 3).

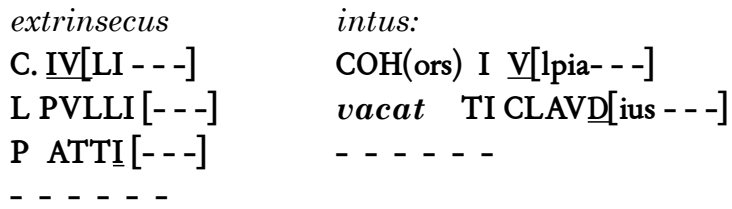

La constatación en la cara interior del nombre de la unidad, la coh. I VIlpia ---], y de su prefecto, Ti. Claud[ius], nos permite confirmar que este fragmento es copia de la constitutio que fue promulgada por el emperador Adriano para las tropas de Siria el 22 de marzo del año 129, y de la que tenemos diversos ejemplos que nos han 

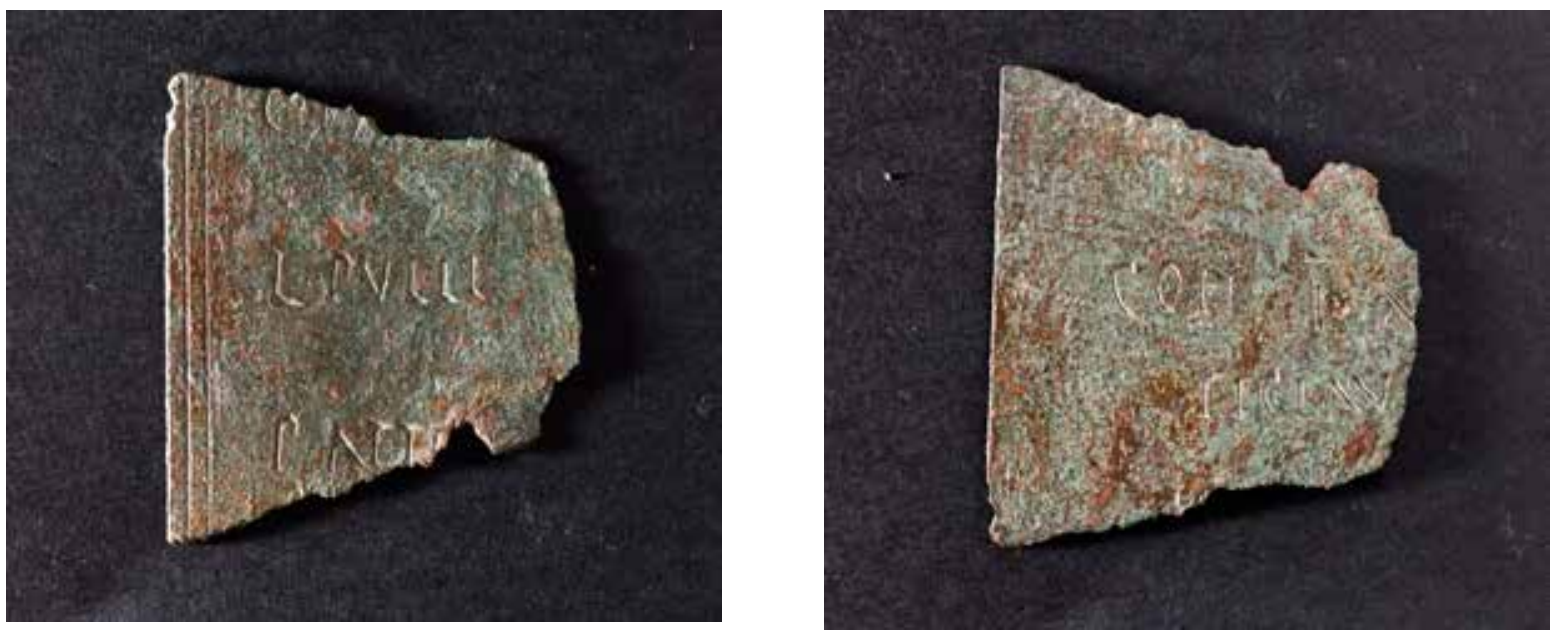

Fig. 3. Detalle del diploma en el que se aprecian parte de los nombres de los testigos.

permitido la reconstrucción total de la misma. Entre estos diplomas destacan de forma particular cinco que fueron emitidos para los veteranos de la cohors I Ulpia Dacorum que este año se encontraba bajo el mando de Ti. Claudius Ti. f. Quirina Maximinus (Eck, MacDonald, y Pangerl, 2001:42-45; 2002: 434, 438; Eck y Pangerl, 2006: 205, 243 = AE 2006, 1845-1851); MacDonald, 2006: 97, 100= AE 2006, 1852; Eck y Pangerl, 2012: 234,240).

Esta unidad, reclutada por Trajano el año 103/104 d.C., después de la conquista de la Dacia, habría sido enviada directamente a Siria, por lo que muy probablemente habría participado con éste en la guerra contra los partos. Así, pues, la mayoría de sus miembros, sino todos, en el año 129 habrían cumplido los 25 años de servicio militar, lo que explicaría fácilmente la gran cantidad de diplomas encontrados de esta unidad, pues, aunque al cabo de veinticinco años de servicio la cohors I Ulpia Dacorum, integrada en el momento de su formación por 400 o 500 individuos, hubiese perdido al menos la mitad de sus integrantes, en el momento de su licenciamiento, al cumplirse los veinticinco años de servicio militar, serían 200-250 los militares que recibirían los diplomas acreditativos de su condición de civis Romanus. Por otra parte, seguramente, sino todos, ya tendrían los derechos civiles romanos, según atestigua el nomen Ulpius de uno de estos veteranos y tal vez de un segundo (Eck y Pangerl, 2006: 228,243= AE 2006, 1845, 1849).
En este supuesto ellos no tendrían necesidad de ningún certificado, pero en su lugar de origen, al que probablemente volvería la mayoría, era necesario un documento que justificase que poseían esos derechos, especialmente en lo referente al conubium, es decir, al derecho de poder contraer un matrimonio legal con una mujer peregrina (Eck y Pangerl, 2012: 239).

Aunque no conozcamos el lugar exacto de su hallazgo, debemos deducir que procederá de alguna ciudad de la provincia Bética, lo que resulta particularmente extraño, pues es bien sabido que los veteranos, una vez finalizado su servicio militar, suelen o bien regresar a su lugar de origen o buscar su futuro en las proximidades del lugar donde han permanecido acuartelados. Ninguna de estas dos variantes se da en nuestro diploma, aunque si en los demás publicados hasta el presente, ya que sus editores consideran que procederían de algún punto de los Balcanes orientales. Este hecho nos obliga a pensar en un militar dacio quién al final de su servicio activo, por razones que desconocemos, se ha traslado a la Península Ibérica en busca de un lugar para vivir. Es evidente que esta suposición no deja de ser, por la falta de datos precisos, una mera hipótesis de trabajo.

Curiosamente, y a pesar del gran número de copias de esta constitutio, no disponíamos de una tabella II con la relación de los testigos hasta la publicación del último diploma en 2012, e incluso en éste tan sólo aparecen los nomina y praenomina de cuatro de ellos: C. Iulius, $L$. Pullus, P. Attius y T. Villius. La pérdida de los 
cognomina impide una datación precisa, pues son varios los testigos que tienen estos gentilicios. Los editores muestran cierta prudencia, limitándose a constatar que Gaius Iulius y Lucius Pullus aparecen varias veces en los testimonios del reinado de Adriano; P. Attius dos, (Festus y Severus) y T. Villius otras dos (Heraclida y Agath[--])1. Sin embargo, un examen más detenido de los testimonios reunidos en $R M D \mathrm{~V}$ tal vez nos ayude a acercarnos un poco más a la identidad de estos testigos. Así, por ejemplo, los testigos con la filiación C. Iulius son tres: Silvanus citado entre los años 134-154, Paratus entre 105-124, y Eutychius entre 107-129. pero la elección entre ellos no debería presentar serios problemas, pues, por un lado, las fechas de la actividad de los dos primeros nos obliga a descartarlos, y por otro, C. Iulius Eutychius actúa como testigo en un diploma del 30 de abril del año 129 (RMD 34). Mayores dificultades presenta la identificación de L. Pullius, pues son tres los testigos que firman durante el reinado de Adriano: Daphnus (a. 122-148), Anthus (a. 114-129) y Verecundus (a. 79-129). Sin embargo, pensamos que hay que descartar a Verecundus, pues su última aparición documentada se fecha en el 121 d.C. (RMD 19). La elección entre Daphnus y Anthus es imposible, aunque éste está documentado en el mismo diploma de Iulius Eutyuchius (RMD 34). Por último, la elección entre Attius Festus y Attius Severus se ve facilitada por el hecho de que la primera aparición de Festus se fecha en el año 133 ( $R M D$ 158), lo que evidentemente, a falta de nuevos testimonios, le excluye. Lo mismo ocurre con la elección entre Villius Heraclida y Villius Agath[---], pues la actuación como testigo de Heraclida está documentada una vez en el reinado de Trajano año 107, en tanto que Agath [- - l lo está también una sola vez, pero en el año 133 d.C. ( $R M D$ 158). Es decir, con los datos aportados, creemos factible restituir los testigos de nuestro fragmento, aunque siempre a la espera de nueva documentación:

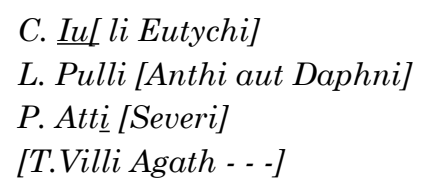

1 Cfr. RMD V, Indices, 939-946.
El texto del diploma según los diversos textos conocidos es el siguiente:

[Imp(erator) Caesar divi Traiani Parthicif(ilius) divi Nervae nepos Traianus Hadrianus Aug(ustus) pontif(ex) max(imus) trib(unicia) potest(ate) XIII co(n)s(ul) III p(ater) p(atriae) equitib(us) et peditib(us), qui militaver(unt) in alis II et coh(ortibus) XI, quae appellantur (1) Aug(usta) Xoitan(a) et (2) I Flav(ia) Agrippian(a) et (1) I Ascalonitanor(um) sagitt(aria) et (2) I Ulp(ia) Dacor(um) et (3) I Ulp(ia) sagitt(aria) c(ivium) R(omanorum) et (4) I Ulp(ia) Petreor(um) sagitt(aria) et (5) II Classica et (6) II Gemina Ligur(um) et Corsor(um) et (7) II Ulp(ia) equit(um) sagitt(aria) c(ivium) R(omanorum) et (8) II Itallic(a) c(ivium) R(omanorum) et (9) III Thrac(um) Syriaca sag]itt(aria) et (10) IIII Callaecorum Lucensium et (11) V Ulp(ia) Petreor(um) sagitt(aria) et sunt in Syria sub Poblicio Marcello, qui quin(is) et vicenis pluribusve stipendiis emeritis dimissis honesta missione],

[quorum nomina subscripta sunt, ipsis liberis posterisque eorum civitatem dedit et conubium cum uxoribus, quas tunc habuissent, cum est civitas iis data aut, si qui caelibes essent, cum iis quas postea duxissent, dumtaxat singuli singulas].

A(nte) d(iem) XI K(alendas) Apr(iles) P(ublio) Iuventio Celso II Q(uinto) Iulio Balbo co(n) s(ulibus)] coh(ortis) I U[lp(iae) Dacor(um), cui praeest] Ti(berius) Claud[ius Ti(beri) f(ilius) Qui(rina) Maximinus Neapol(i) ex pedite - - - .

[Descriptum et recognitum ex tabula aenea quae fi xa est Romae in muro post templum divi Aug(usti) ad Minervam.

- - -]; G(ai) Iu[lii Eutychi]; L(uci) Pulli [Anthi aut Daphni]; P(ubli) Atti [Severi]; [T(iti) Villi Agath - - -].

En síntesis, se presenta en este trabajo esta pequeña colección que sin duda viene a aportar más conocimiento a la diplomatica militaria de Hispania. Hay fragmentos de muy pobre contenido, que impiden una restitución significativa, mientras que otros, con más texto conservado, permiten una restitución parcial y su identificación con las unidades militares mencionadas. 
BibLIOGRAFÍA

Eck, W., MacDonald, D., y Pangerl, A. (2001), "Neue Diplome für die Auxiliartruppen in den Dakischen Provinzen", Acta Musei Napocensis, 38,1, 42-45.

(2002), "Neue Diplome für das Heer der Provinz Syrien", Chiron 32, 434-438

Eck, W., y Pangerl, A. (2006): "Syria unter Domitian und Hadrian: Neue Diplome für die Auxiliartruppen der Provinz", Chiron 36, 205, 243.

(2012), "Zwei neue Diplome für die Provinz Syria aus domitianicher und Hadrianischer Zeit", ZPE 183, 234-240.

González, J., y Bermejo, J. (e.p.), "Un nuevo diploma militar de Mauritania Tingitana", Epigraphica LXXVIII.

MacDonald, D. (2006), "New fragmentary Diploma of the Syrian Army, 22 March 129”, SCI 25, 97-100. 
